\title{
EVALUATION OF SCROTAL PATHOLOGY BY HIGH RESOLUTION ULTRASOUND AND COLOUR DOPPLER
}

\author{
Pintu Biswas ${ }^{1}$, Asim De $^{2}$
}

${ }^{1}$ Senior Resident, Department of Radiodiagnosis, Agartala Government Medical College and G. B. Pant Hospital, Agartala, Tripura. ${ }^{2}$ Associate Professor, Department of Radiodiagnosis, Agartala Government Medical College and G. B. Pant Hospital, Agartala, Tripura.

\section{ABSTRACT}

\section{BACKGROUND}

Clinical diagnosis of a scrotal swelling is not straightforward. It is often difficult to decide whether a palpable scrotal mass is intratesticular or extratesticular. Moreover, the clinical examination may over look significant pathology and physical signs elicited may be improperly interpreted. The sonogram with high frequency linear transducer and colour Doppler is invaluable in evaluating scrotum and its contents. Sonography is simple to perform, rapid, non-invasive, relatively inexpensive, easily reproducible, widely available and does not expose the gonads to radiation.

Aim and Objective- To evaluate various scrotal pathologies using ultrasonography and to describe the role of high resolution ultrasound and colour Doppler in their diagnosis.

\section{MATERIALS AND METHODS}

Fifty patients were descriptive studied over a period of 8 months from July '16 - Feb '17 using high-frequency real time gray scale ultrasonography and colour Doppler in our institution.

\section{RESULTS}

Out of total 50 cases non-inflammatory pathologies were seen in 26 cases (52\%), whereas inflammatory pathologies in 20 cases (40\%). Among the inflammatory scrotal diseases, incidences of various pathologies were acute epididymo-orchitis- 8 cases $(40 \%$ of inflammatory category), chronic epididymo-orchitis- 4 cases (20\%), acute and chronic epididymitis- 2 (10\%) cases each. Among non-inflammatory pathologies, incidences of various pathologies were: hydrocele- in 23 cases ( $46 \%$ of total); epididymal cyst in 3 cases; varicocele, torsion, tumour, inguinal hernia and traumatic epididymitis- 1 case each (3.84\%).

\section{CONCLUSION}

High frequency ultrasonography is highly sensitive in differentiating solid from cystic scrotal masses. Colour Doppler sonography is highly sensitive in diagnosing acute scrotal pathology, differentiating testicular torsion from acute inflammatory diseases and in demonstrating sub-clinical cases of varicocele.

\section{KEYWORDS}

Colour Doppler, Epididymoorchitis, Fournier's Gangrene, High Resolution Ultrasonography, Scrotum.

HOW TO CITE THIS ARTICLE: Biswas P, De A. Evaluation of scrotal pathology by high resolution ultrasound and colour Doppler. J. Evolution Med. Dent. Sci. 2017;6(34):2820-2827, DOI: 10.14260/Jemds/2017/607

\section{BACKGROUND}

Scrotum is a cutaneous pouch which contains the testes, both epididymis and the lower part of both spermatic cords. It is formed by the fusion of two scrotal sacs separated by an inner septum that corresponds a midline ridge or raphe, which is continued forward to the under-surface of the penis and backwards along midline of the perineum to the anus.

Since the ancient times, scrotal pathologies have been cause of apprehension and anxiety on part of both the patient and clinician.[1] During clinical examination of the scrotal pathology, physical evaluation by itself may be inadequate due to tenderness, swelling or gross distortion of scrotal contents. In addition, the normal examination may overlook significant pathology and physical signs elicited may be improperly interpreted.[2]

Financial or Other, Competing Interest: None.

Submission 05-04-2017, Peer Review 18-04-2017,

Acceptance 20-04-2017, Published 27-04-2017.

Corresponding Author:

Dr. Pintu Biswas,

Room No. 18, P. G. Family Quarters,

Agartala Government Medical College and G. B. Pant Hospital,

P. O. Kunjaban, Agartala, Tripura.

E-mail: biswaspintu54@gmail.com

DOI: $10.14260 /$ jemds $/ 2017 / 607$
Many of the scrotal disease processes like testicular torsion and epididymoorchitis produce common symptom of pain at presentation, and differentiation of these conditions and disorders is important for determining the appropriate treatment.

Ultrasound with colour Doppler, magnetic resonance imaging, testicular angiography and radioisotope studies are now first line of investigations used for various scrotal pathologies.[3] Computed tomography exposes testicles to the radiation. MRI gives the detailed anatomic imaging and provides a certain degree of tissue specificity. However, MRI is not easily available and its high cost resulting in its limitation for routine examination.

High-resolution ultrasonography enables in clear demonstration of morphological alterations associated with scrotal inflammatory diseases, but has the limitations because it does not enable assessment of perfusion of scrotum and its contents. When colour Doppler sonography is supplemented with high frequency grey scale US, the sensitivity of diagnosing acute scrotal pathology is increased. In addition, colour Doppler sonography accurately differentiates between testicular ischaemia and torsion from acute inflammatory diseases in acute painful scrotal conditions. 


\section{MATERIALS AND METHODS}

This descriptive study was conducted at the Department of Radiodiagnosis at Agartala Government Medical College and G. B. Pant Hospital, Agartala, Tripura. We studied fifty (50) patients over a period of 8 months from July '16 - Feb '17, to evaluate various scrotal pathologies using ultrasonography and describe the role of high resolution ultrasound and colour Doppler in their diagnosis. All patients who had clinical manifestation of any scrotal pathology were included in the study. Haemodynamically unstable patients and those patients who did not give the consent for study were excluded.

Prior to subjecting the patients for ultrasound examination, patient details, detail clinical history was obtained along with thorough physical examination.

The study was performed using 7.5 to $10 \mathrm{MHz}$ linear transducer. Siemens Acuson X300 ultrasound and Doppler machine was used. The colour Doppler sonography was routinely performed in all patients.

Abdominal ultrasonography was performed in conjunction with the scrotal scans using 3.5 to $5.0 \mathrm{MHz}$ convex curved array transducer whenever required, like in patients of tubercular epididymoorchitis, in patients of testicular malignancy, in patients of varicocele and in undescended testes.

\section{Scanning Technique}

Scanning was routinely performed in supine position, after elevating scrotum using a towel draped over thighs and the penis was placed on the patient's abdomen and covered with a towel. The hemi scrota were examined in transverse, sagittal and oblique planes.

Transverse side by side images were taken to compare the echogenicity and vascularity of both testes. Additional positions and manoeuvres like standing, Valsalva manoeuvres were used whenever required (as in case of a varicocele). Spermatic cord and inguinal regions were scanned in special circumstances like encysted hydrocele of cord, in varicocele to know the complete extension and in epididymitis to look for funiculitis and in undescended testis cases.

Size, shape, echogenicity, echotexture, vascularity (on colour and power Doppler mode) of testes and epididymis was examined routinely in all cases. In a case of focal scrotal lesion in addition to above-mentioned parameters, location (intratesticular/extratesticular), laterality (unilateral/ bilateral), margin and presence of any calcification were noted. Thickness and vascularity of the cord and also the thickness, echotexture and vascularity of scrotal skin were routinely examined. Any collection in scrotal sac and its nature were evaluated.

\section{Statistical Analysis}

Data has been expressed in number and in frequency in terms of percentage wherever felt necessary. Statistical Package for the Social Sciences (SPSS) software programme (Version 15) was used for data analysis.

\section{RESULTS}

Fifty cases of scrotal swellings were studied with real time high frequency ultrasonography and colour Doppler sonography.
Most of the subjects were in the age group of 21 to 30 years, which constituted 28\% (14 nos.) of total cases [Refer to Table No. 1].

Commonest clinical presentation was painless scrotal swelling, which alone constituted $50 \%$ (25 nos.) of all pathologies. This was followed by painful scrotal swelling constituting approximately $34 \% \quad(17$ nos.) [Refer to Table No. 2].

Non-inflammatory pathologies were most common seen in 26 cases $(52 \%)$, whereas inflammatory pathologies were seen in 20 cases (40\%) and no pathology was seen in 4 cases (8\%) [Refer to Table No. 3].

Among the inflammatory scrotal diseases, acute epididymo-orchitis was the leading cause, were seen in 8 cases (40\% of inflammatory category) [Figure 1] followed by chronic epididymo-orchitis which were seen in 4 cases (20\%). Acute epididymitis [Figure 2] and chronic epididymitis were seen in $2(10 \%)$ cases each.

Funiculitis and scrotal wall cellulitis were seen in $3(15 \%)$ cases in each category. One case of testicular abscess (5\%) and one case (5\%) of Fournier's gangrene [Figure 3] was seen [Refer to Table No. 4].

Focal testicular infarctions [Figure 4] were noted in two of acute epididymoorchitis cases. Testicular atrophy was seen in one chronic epididymoorchitis case.

Hydrocele, the commonest type of non-inflammatory scrotal pathology was seen in 23 cases ( $46 \%$ of total case), though total 39 cases of hydrocele were seen; 16 no. of hydrocele cases were inflammatory. Varicocele was seen in 1 case (3.84\%, out of 26 non-inflammatory cases) [Figure 5] Torsion [Figure 6], tumour [Figure 7], inguinal hernia [Figure 8] and traumatic epididymitis were also seen in one case each (3.84\%). Epididymal cysts (non-inflammatory) were seen in three cases $(11.53 \%)$. Intratesticular cyst and cyst of tunica albuginea were also noted in one case $(3.84 \%)$ in each category [Refer to Table No. 5].

\begin{tabular}{|c|c|c|}
\hline Age Group & No. of Cases & Percent \\
\hline $01-10$ & 2 & 4.0 \\
\hline $11-20$ & 8 & 16.0 \\
\hline $21-30$ & 14 & 28.0 \\
\hline $31-40$ & 9 & 18.0 \\
\hline $41-50$ & 7 & 14.0 \\
\hline $51-60$ & 8 & 16.0 \\
\hline $61-70$ & 1 & 2.0 \\
\hline $71-80$ & 1 & 2.0 \\
\hline Total & 50 & 100.0 \\
\hline Table 1. Age Distribution of Patients of this Study \\
\hline
\end{tabular}

\begin{tabular}{|c|c|c|}
\hline Presenting Complaints & No. of Cases & Percent \\
\hline Painful Swelling & 17 & 34.0 \\
\hline $\begin{array}{l}\text { Painful Swelling with } \\
\text { History of Trauma }\end{array}$ & 2 & 4.0 \\
\hline Painless Swelling & 25 & 50.0 \\
\hline Pain without Swelling & 5 & 10.0 \\
\hline Others & 1 & 2.0 \\
\hline Total & 50 & 100.0 \\
\hline \multicolumn{3}{|c|}{ Table 2. Presenting Complaints } \\
\hline
\end{tabular}




\begin{tabular}{|c|c|c|}
\hline Type of Pathology & No. of Cases & Percent \\
\hline Inflammatory & 20 & 40.0 \\
\hline Non-Inflammatory & 26 & 52.0 \\
\hline No. Pathology Detected & 4 & 8.0 \\
\hline Total & 50 & 100.0 \\
\hline
\end{tabular}

\begin{tabular}{|c|c|c|c|c|c|}
\hline \multirow{2}{*}{\multicolumn{2}{|c|}{$\begin{array}{c}\text { Pathology } \\
\text { Epididymoorchitis }\end{array}$}} & \multicolumn{2}{|c|}{ No. of Cases } & \multirow{4}{*}{$\begin{array}{c}\text { Comment } \\
- \\
-\end{array}$} & \multirow{4}{*}{\begin{tabular}{|c|}
$\%$ \\
$\begin{array}{c}\text { Out } \\
\text { of } 20 \\
\text { cases }\end{array}$ \\
40 \\
\end{tabular}} \\
\hline & & \multirow{3}{*}{$\begin{array}{c}\begin{array}{c}\text { Sub- } \\
\text { total }\end{array} \\
7 \\
1\end{array}$} & \multirow{3}{*}{$\begin{array}{c}\text { Total } \\
8\end{array}$} & & \\
\hline \multirow{2}{*}{ Acute } & RT & & & & \\
\hline & LT & & & & \\
\hline \multirow{3}{*}{ Chronic } & RT & 1 & \multirow{3}{*}{4} & \multirow{4}{*}{ - } & \multirow{4}{*}{20} \\
\hline & LT & 1 & & & \\
\hline & BIL & 2 & & & \\
\hline \multicolumn{2}{|c|}{ Epididymitis } & & & & \\
\hline \multirow[b]{2}{*}{ Acute } & RT & 1 & \multirow[b]{2}{*}{2} & & \multirow[b]{2}{*}{10} \\
\hline & LT & 2 & & $\begin{array}{c}1 \text { is non- } \\
\text { inflammatory- } \\
\text { i.e. traumatic } \\
\text { epididymitis }\end{array}$ & \\
\hline Chronic & RT & - & 2 & - & 10 \\
\hline
\end{tabular}

\begin{tabular}{|c|c|c|c|c|c|}
\hline & LT & 2 & & & \\
\hline Funiculitis & 3 & - & $\begin{array}{c}\text { All 3 included in } \\
\text { acute epidi- } \\
\text { dymoorchitis }\end{array}$ & - \\
\hline Scrotal wall cellulitis & 2 & $\begin{array}{c}\text { Total 3; 1 is } \\
\text { included in } \\
\text { epididymitis }\end{array}$ & 10 \\
\hline Testicular abscess & & 1 & - & 5 \\
\hline Fournier's Gangrene & 1 & - & 5 \\
\hline \multicolumn{2}{|c|}{ Total } & \multicolumn{2}{|c|}{20} & - & $\mathbf{1 0 0}$ \\
\hline \multicolumn{2}{|c|}{ Table 4. Inflammatory Scrotal Pathology } \\
\hline
\end{tabular}

Footnotes:* RT- Right, † LT- Left, ‡ BIL- Bilateral

\begin{tabular}{|c|c|}
\hline Pathology & No. of Cases \\
\hline Hydrocele & 23 \\
\hline Epididymal Cyst & 3 \\
\hline Inguinal Hernia & 1 \\
\hline Traumatic Epididymitis & 1 \\
\hline Torsion & 1 \\
\hline Neoplasia & 1 \\
\hline Intratesticular Cyst & 1 \\
\hline Cyst of Tunica Albuginea & 1 \\
\hline \multicolumn{2}{|c|}{ Varicocele } \\
\hline \multicolumn{2}{|c|}{ Table 5. Non-Inflammatory Cases } \\
\hline
\end{tabular}

\begin{tabular}{|c|c|c|c|c|c|c|c|c|c|c|c|c|c|c|c|}
\hline \multirow[t]{2}{*}{ Pathology } & \multicolumn{3}{|c|}{ Size of Testis } & \multicolumn{3}{|c|}{ Size of Epid } & \multicolumn{3}{|c|}{ Echogenicity } & \multicolumn{3}{|c|}{ Echotexture } & \multicolumn{3}{|c|}{ Vascularity } \\
\hline & 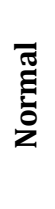 & 胥 & 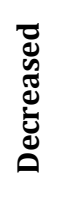 & ż̃ & 产 & 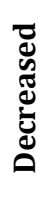 & हี & 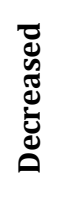 & 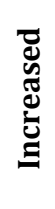 & ב⿱艹 & 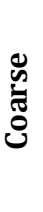 & 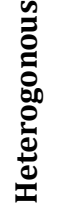 & ב⿱艹 & 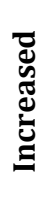 & 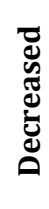 \\
\hline $\begin{array}{c}\text { Acute } \\
\text { Epididymoorchitis } \\
\text { (8 nos.) }\end{array}$ & 3 & 5 & - & - & 8 & - & 1 & 7 & - & - & 6 & 2 & - & 8 & - \\
\hline $\begin{array}{c}\text { Chronic } \\
\text { Epididymoorchitis } \\
\text { (4 nos.) }\end{array}$ & 3 & - & 1 & 1 & 3 & - & - & 1 & 3 & - & 3 & 1 & 1 & 2 & 1 \\
\hline $\begin{array}{l}\text { Acute Epididymitis } \\
\text { (3 nos.) }\end{array}$ & 2 & 1 & - & 1 & 2 & - & 1 & 2 & - & 1 & 1 & 1 & - & 3 & - \\
\hline $\begin{array}{l}\text { Chronic Epididymitis } \\
\text { ( } 2 \text { nos.) }\end{array}$ & 2 & - & - & - & 2 & - & 1 & - & 1 & - & - & 2 & - & 2 & - \\
\hline
\end{tabular}

\begin{tabular}{|c|c|c|c|c|c|c|}
\hline Study & Epididymoorchitis (\%) & Epididymitis (\%) & Funiculitis (\%) & Scrotal Wall Cellulitis (\%) \\
\hline & Acute & Chronic & Acute & Chronic & & 15 \\
\hline This study & 40 & 20 & 10 & 10 & 7.14 & 7.14 \\
\hline Melkundi et al & 25 & 39.3 & 8.3 & 8.3 & - & 3.1 \\
\hline Mathukumili et al & 21.8 & 37.5 & 18.5 & 6.2 & 7.14 & - \\
\hline Narra et al & 36 & 7.14 & 21 & 7.14 & - & - \\
\hline Horstman et al & 42 & - & 56 & - & & - \\
\hline Lerner et al & 40 & & 60 & & & 7.5 \\
\hline Farriol et al & 30 & 20 & 10 & 5 & - & \\
\hline Patil \& Shetty & \multicolumn{7}{|c|}{ Table 7. Comparisons of Incidence of Epididymitis, Epididymoorchitis, } \\
\hline \multicolumn{7}{|c|}{ Funiculitis and Scrotal Wall Cellulitis of this Study to other Study } \\
\hline
\end{tabular}


Some Relevant Images of the Study

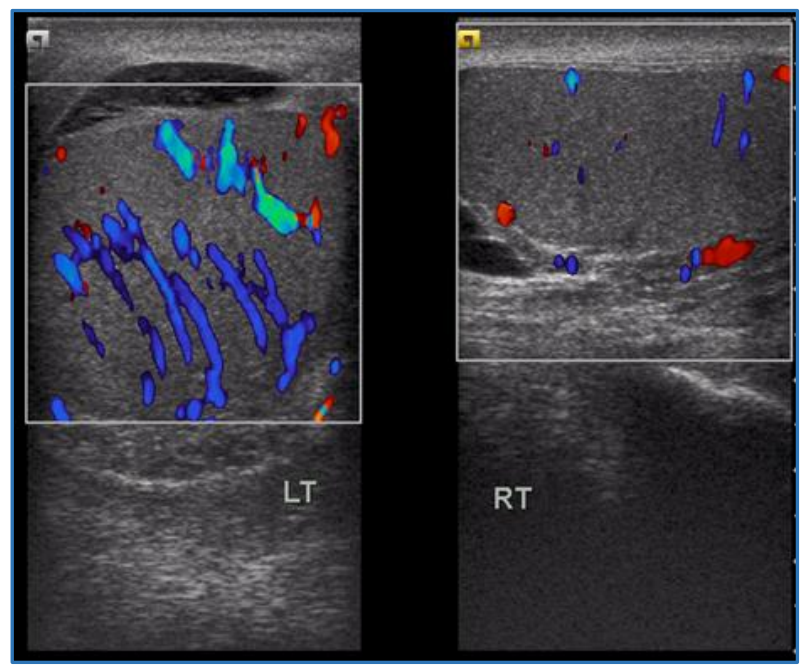

Figure 1. Acute Epididymoorchitis: Colour Doppler Dual Image shows Increased Vascularity in Left Testis. Minimal collection seen bilaterally. The Left Head of Epididymis was Bulky, Heterogeneous and Hypervascular (Not Shown)
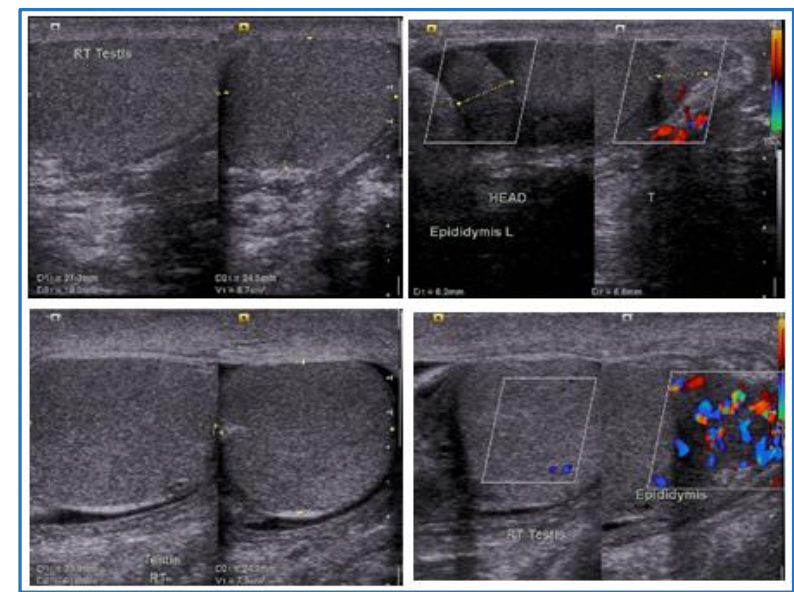

Figure 2. Acute Epididymitis (Right): The Right Epididymis is Bulky and Hyperaemic (Left Lower Image). The Left Epididymis and both Testes appear Normal. Minimal Free Fluid present Bilaterally (Left > Right)

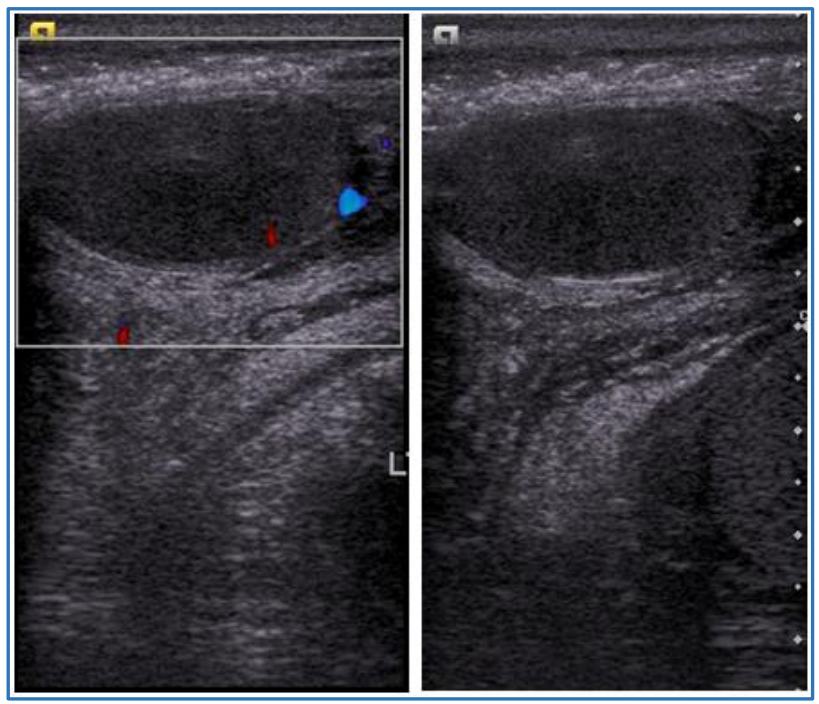

Figure 3. Fournier's Gangrene: Longitudinal Image (Gray Scale and Colour Doppler) shows Thickening and Loss of Normal Hyperechogenicity associated with Subcutaneous Gas in the Left Scrotal Wall

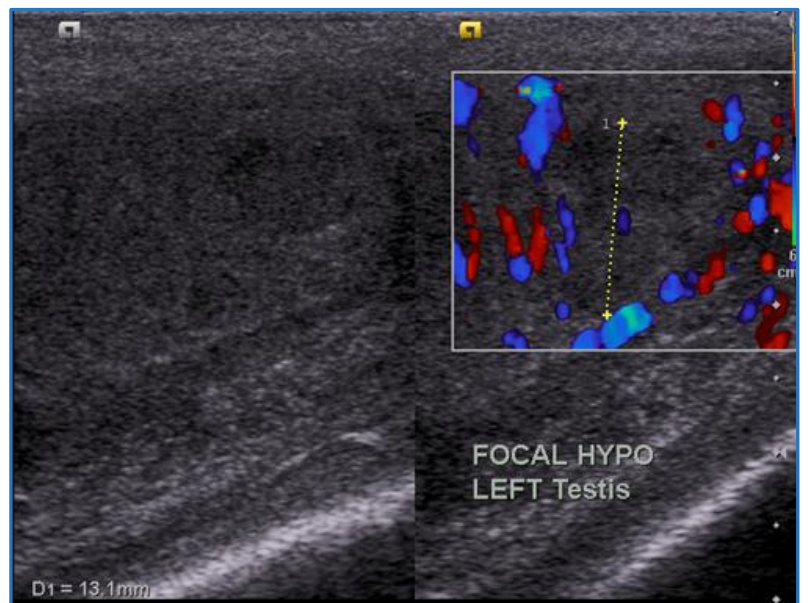

Figure 4. Acute Epididymoorchitis with Focal Testicular Infarction: Dual Image USG shows a Small Hypoechoic Area in Left Testis with Coarse Echotexture in Gray Scale (Right). In the Left Image Colour Doppler USG shows Increased Vascularity in Left Epididymis and Adjacent Part of Testis except in the Focal Hypoechoic Area which is Avascular

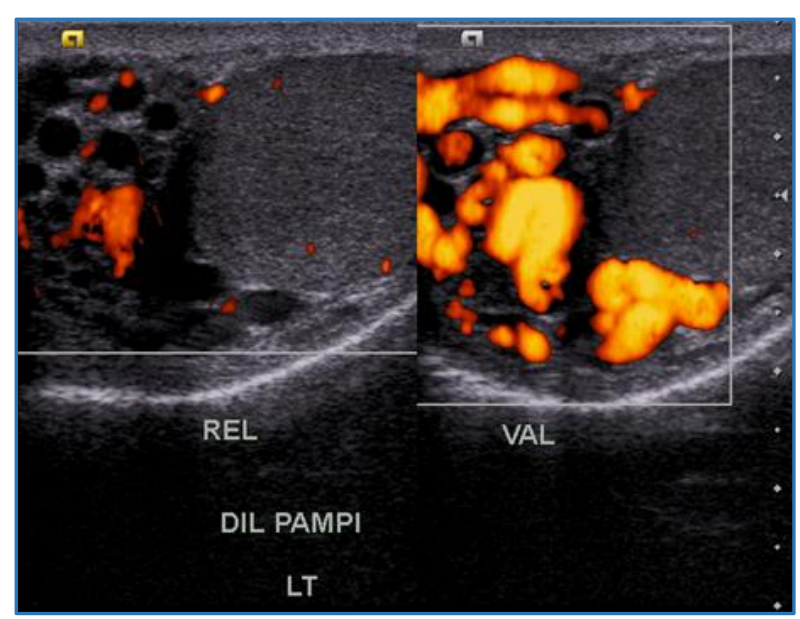

Figure 5. Varicocele. Colour Doppler Image shows Multiple Anechoic Structures creating a Tortuous, Multicystic Collection located Adjacent to the Upper Pole of the Testis and Head of the Epididymis. These are distended following Valsalva Manoeuvre and Decompressed after release of Valsalva

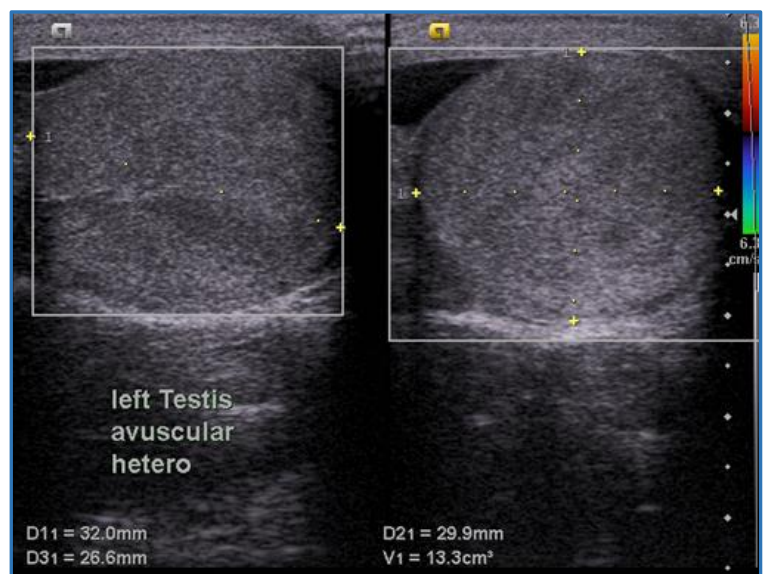

Figure 6. Torsion of Testis- Dual (Longitudinal and Transverse) Image of Left Testis shows Avascular Heterogeneous Testis. Minimal Hydrocele is Noted 


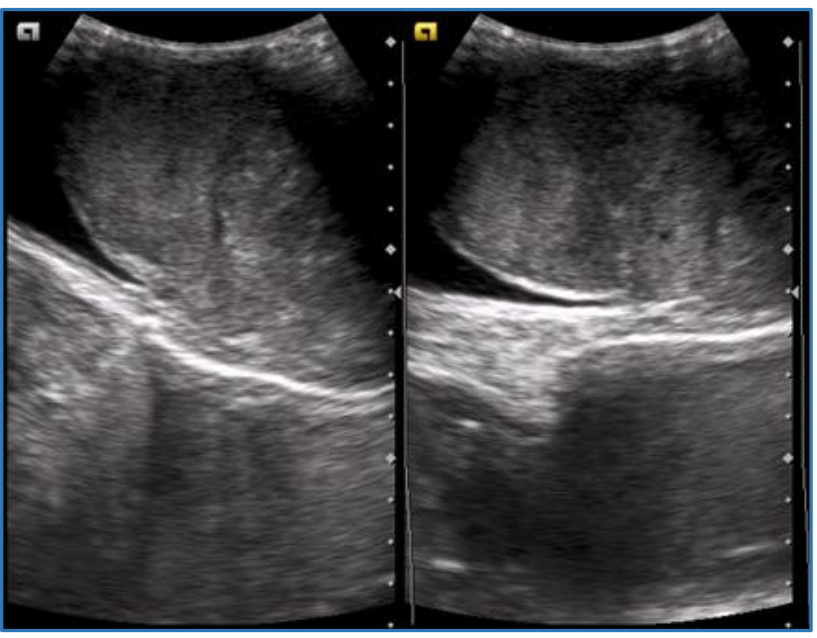

Figure 7. Multifocal Seminoma: HRUS Image shows whole Left Testis was replaced by IIl-Defined Multifocal Homogenously Hypoechoic Mass

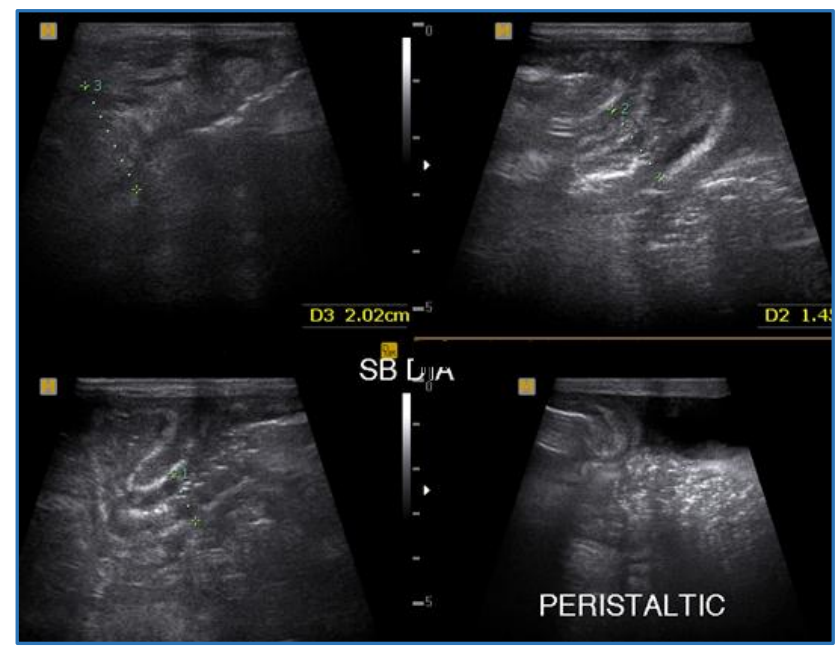

Figure 8. Scrotal Hernia: HRUS shows Small Bowel Loops in Right Hemiscrotum. Real Time USG revealed Peristalsis in Bowel Loops

\section{DISCUSSION}

Most of the subjects in this study were in the age group of 21 to 30 years, which constituted $28 \%$ of total cases ( 14 nos.). It is similar to the study of 100 cases by Mathukumili $C$ and Bahaddur A, where 21 to 30 years' age group was most commonly affected (24 cases, 24\%).[4]

Commonest clinical presentation was painless scrotal swelling, which alone constituted 50\% (25 nos.) of all pathologies. This was followed by painful scrotal swelling constituting approximately 34\% (17 nos.). Including two cases of trauma which caused painful swelling, scrotal swelling with or without pain were $88 \%$ (44 nos.). In their study of 50 cases, Melkundi et al also noted that commonest clinical presentation was scrotal swelling with or without pain.[5]

In this study, inflammatory conditions were seen in 20 cases $(40 \%)$ and non-inflammatory cases were in 26 (52\%) cases.

Arger et al in a series of 62 patients detected the inflammatory diseases in 16 cases (26\%) and noninflammatory diseases in 45 cases (67\%).[6] Willscher et al in a study of 43 patients noted the inflammatory diseases in 12 cases (28\%), non-inflammatory diseases in 28 cases (65\%). ${ }^{[7]}$ In the study by Melkundi et al, the bulk of the pathology detected by high-resolution US were from two groups: Inflammatory pathologies (28 cases- 56\%) and noninflammatory swellings (22 cases- 44\%).[5]

Thus, it is obvious that the types of pathology (Inflammatory and Non-Inflammatory) detected in this study correlates with findings documented in previous studies.

\section{Inflammatory Pathology}

In our study, out of 50 cases 20 cases were detected to have inflammatory scrotal pathology on high frequency US and colour Doppler.

\section{Epididymoorchitis and Epididymitis}

Among the inflammatory pathologies acute epididymoorchitis was the commonest, noted in 8 cases (40\%). Horstman et al in their study of 45 patients found acute epididymo-orchitis in 19 cases (42\%).[8] Lerner et al in their limited series of 5 cases of acute inflammatory diseases of scrotum, acute epididymo-orchitis in 2 patients (40\%).[9] Narra et al in their study of 60 cases detected 14 cases of inflammatory pathology, out of which acute epididymoorchitis was the commonest seen in 5 cases (36\%).[10]

Next most frequent inflammatory pathology detected in our study was chronic epididymo-orchitis noted in 4 cases (20\%). In the study of 100 cases by Patil V and Shetty SMC, chronic epididymo-orchitis was detected in 8 patients (20\%).[11]

Acute epididymitis was seen in this study in 2 cases (10\%). In their study by Patil V and Shetty SMC, acute epididymitis was seen in 4 patients $(10 \%) .[11]$

We detected chronic epididymitis in 2 cases (10\%). Melkundi et al detected chronic epididymitis in 3 cases (8.3\%).[5]

From the above discussion, it is clear that, frequency of acute epididymoorchitis, chronic epididymoorchitis and acute epididymitis are consistent and that of chronic epididymitis is comparable with the previous studies.

\section{Funiculitis}

Total three cases $(15 \%)$ of funiculitis were seen. Two cases were associated with epididymoorchitis and one case with epididymitis. There were thickened spermatic cords with increased vascularity.

\section{Scrotal Wall Cellulitis}

In the cases of scrotal wall cellulitis, ultrasonographic finding was thickening and loss of uniform hyperechogenicity of the scrotal wall with normal testis and epididymis. Among three such cases (15\%), two were isolated and one was with left acute epididymitis.

The incidence of funiculitis and scrotal wall cellulitis in this study were $15 \%$ (3 cases) in both. Various literatures.[4,5,10-12] reveal that the incidence of funiculitis and scrotal wall cellulitis ranges from $7.14 \%$ to $8 \%$ and $3.1 \%$ to $7.5 \%$ respectively. These slight higher levels in our study is probably because of very careful clinicoradiological evaluation of the scrotum.

Out of 8 cases of acute epididymoorchitis, we observed diffuse hypoechogenicity in 7 cases, coarse echotexure in 6 
cases and diffuse increase in vascularity in all 8 cases. Size of the involved testis was bulky in 5 and that of epididymis in all. Out of 4 cases of chronic epididymoorchitis, we observed slightly increased echogenicity in 3 cases, heterogeneous echotexture in 1 case and coarse echotexture in 3 cases and increase in vascularity in 2 cases. Size of the involved testis and epididymis was normal in 3 cases each. Out of 3 cases of acute epididymitis, we observed diffuse hypoechogenicity in 2 cases and increase in vascularity in all. Size of epididymis was bulky in 2 cases. Both the cases of chronic epididymitis showed thickened, irregular epididymis with heterogeneous echotexture and hypervascularity. In both cases, testes were normal in size [Refer to Table No. 6].

These sonographic findings are nearly similar to the finding of Mathukumili C and Bahaddur A.[4]

\section{Tubercular Epididymoorchitis}

In this study, we have found a case where High Resolution Ultrasonography (HRUS) revealed diffusely enlarged heterogeneously hypoechoic epididymis and coarse echotexture of testis associated with multiseptated hydrocele and thickened scrotal skin in right hemiscrotum, which was diagnosed as a case of tubercular epididymoorchitis. FNAC was suggested. Table no. 7 shows comparison of incidence of epididymoorchitis, epididymitis, funiculitis and scrotal wall cellulitis of various literatures.

\section{Pyocele}

In this study two cases $(10 \%)$ of pyocele were seen where there were complex, heterogeneous fluid collection with septae in the ipsilateral scrotal sac. Both the cases were associated with acute epididymitis. This is comparable to finding by Melkundi et al, who observed pyocele in 4 cases (14.28\%) cases.[5]

\section{Fournier's Gangrene}

On HRUS, thickening and fluid collection and loss of normal hyperechogenicity of scrotal wall associated with subcutaneous gas in the scrotal wall was seen in a case, which was diagnosed as Fournier's gangrene. In the study by Patil V and Shetty SMC, Fournier's gangrene was seen in 1 case (2.5\%).[11] Mathukumili $\mathrm{C}$ and Bahaddur A- detected it in $6.2 \%$ of cases ${ }^{[4]}$ and Narra et al[10] found it in 1 case $(7 \%)$. We observed Fournier's gangrene in 1 case (5\%), which is quite consistent to finding of previous studies.

\section{Testicular Abscess}

In this study, 1 case (5\%) of testicular abscess was detected. On HRUS, it showed an enlarged right testicle with disrupted testicular architecture, containing a predominantly fluidfilled mobile low level echogenic avascular collection. Testicular abscess were observed in 3 cases (7.5\%) by Patil V and Shetty SMC.[11] This discrepancy was likely due to early diagnosis and efficient management of predisposing condition like epididymoorchitis in this state.

\section{Non-Inflammatory Pathologies Hydrocele}

Total thirty nine $(78 \%)$ cases of hydrocele were seen in this study. Sonographically, there were anechoic collections surrounding the anterolateral aspects of the testis. Low-level to medium-level echoes were visualised in many cases moving freely within hydrocele.

Sixteen (41.02\% out of 39 cases) were inflammatory and twenty-three cases $(58.97 \%$, out of 39 cases) were noninflammatory.

Out of thirty-nine cases, 12 cases (30.76\%) were primary containing large amount of fluid. These were painless and were otherwise asymptomatic, other than size and weight, causing some inconvenience. 26 cases (66.66\%) were secondary type. These were lax and of moderate size and mostly associated with epididymo-orchitis. 15 cases $(38.46 \%)$ were unilateral and 24 cases $(61.53 \%)$ were bilateral.

Melkundi et al also noted that hydrocele was the commonest non-inflammatory pathology. They found 22 noninflammatory cases, among which hydrocele were noted in 14 cases (28\%).[5] In a prospective study of 100 cases by Rathi et al, out of total 22 cases of hydrocele, primary hydrocele was seen in 7 seven cases (31.81\%) and secondary hydrocele in 15 cases (68.18\%).[1] In the present study, primary and secondary hydrocele was seen in $30.76 \%$ and $66.66 \%$ cases respectively, which are very close to study by Rathi et al[1] as discussed above.

In this study in one case $(2.56 \%$ out of total hydrocele cases), USG of inguinal region showed elongated fluid collection above the level of the testis and epididymis suggestive of hydrocele of cord, which is comparable to the study by Patil V and Shetty SMC, where encysted hydrocele was detected in 1 case (5\%).[11]

High incidence of hydrocele was noted in this study (78\%). Various similar studies show that the incidence of hydrocele is $19 \%$ to $28 \% \cdot[1,5,11]$

\section{Epididymal Cysts}

Epididymal cysts were small unilocular simple cystic lesions and involving the head of epididymis. Total 7 cases (14\%) had epididymal cyst which is comparable to the finding of Melkundi et al, where they detected 5 cases $(10 \%)$ of epididymal cysts.[5]

In our study, out of 7 cases of epididymal cyst, 4 cases were associated with inflammatory scrotal disease and 3 cases were non-inflammatory. Single cyst was seen in 4 cases and multiple cysts were noted in 3 cases. Among these 3 cases of multiple epididymal cysts, unilateral multiloculated cysts were in 2 cases $(28.57 \%)$. These findings are close to the finding of Melkundi et al, where they detected 1 case of unilateral multiloculated (20\%) epididymal cyst out of total 5 cases. ${ }^{[5]}$

\section{Traumatic Epididymitis}

One case (3.8\% of non-inflammatory category) of traumatic epididymitis was seen in this study (among the three cases with history of trauma), where the involved left epididymis was enlarged, heterogeneous and hyperaemic. Similar sonographic finding was noted by Gorden et al in their study of 5 cases.[13] This was associated with low level echogenic collection with septations in the ipsilateral scrotal sac suggestive of haematocele. Gorden et al observed haematocele in 2 cases $(40 \%)$ out of 5 cases of traumatic epididymitis.[13] Melkundi et al noted haematocele in all the 5 cases of testicular trauma (100\%).[5] We observed haematocele in 1 case out of 3 cases with history of trauma 
(33.33\%). This discrepancy could be due to less number of traumatic cases included in our study.

\section{Varicocele}

In this series, one case $(3.84 \%)$ of varicocele was detected. Clinically, the case presented with unilateral scrotal swelling with mild discomfort but was not diagnosed as a case of varicocele. On gray-scale USG there were multiple, serpentine, anechoic structures measuring up to $3.4 \mathrm{~mm}$ in diameter, creating a tortuous, multicystic collection located adjacent to the upper pole of the testis and head of the epididymis (left side). Colour Doppler USG reveals the typical venous flow pattern. These were distended following Valsalva manoeuvre and decompressed after release of Valsalva. These results indicate that HRUS with colour Doppler sonography is having high sensitivity in diagnosis of varicocele compared to physical examination. Literatures show that the incidence of varicocele ranges from 9 to $26 \% .[1,5,10,11]$ Compared to existing literature, the incidence of varicocele was found to be significantly less.

\section{Scrotal Hernia}

There was 1 case $(3.84 \%)$ of scrotal hernia in this study. The hernia contained small bowel loops. On real-time examination, peristalsis was detected. This is almost similar to the finding by Patil V and Shetty SMC, where scrotal hernia was detected in 1 case (2\%).[11]

\section{Torsion}

One case $(3.84 \%)$ of torsion was seen in the present study where the left testis and epididymis was bulky and avascular with decreased echogenicity and coarse echotexture following minor degree of trauma in left hemiscrotum. Bilateral hydrocele was seen in the case (Left $>$ Right).

Rathi et al[1] noted torsion in 10 cases $(10 \%)$ and Patil V and Shetty SMC[11] noted it in 5 cases (11\%). Melkundi et al noted torsion in 5 cases $(10 \%)$, where left testis was involved in 3 cases.[5] This discrepancy was due to large sample size in the former two studies and more number of traumatic cases in the third study of (Melkundi et al).

Gray scale sonography could not confidently diagnose the torsion. Prompt diagnosis is necessary because torsion requires immediate surgery to preserve the testis. The testicular salvage rate is $80 \%$ to $100 \%$ if surgery is performed within 5 to 6 hours of the onset of pain, $70 \%$ if surgery is performed within 6 to 12 hours and only $20 \%$ if surgery is delayed for more than 12 hours. ${ }^{[14]}$ Here lies the significant role of colour Doppler, which promptly revealed absent vascularity in left testis and epididymis.

\section{Seminoma}

We detected one neoplastic case (3.84\%) in a 35 years old male, who presented with painless diffuse left testicular swelling, where the whole left testis was replaced by illdefined multifocal homogeneously hypoechoic mass. The ipsilateral epididymis was indistinct. There were multiple enlarged heterogeneous retroperitoneal lymph nodes. The case was sonographically diagnosed as multifocal seminoma. This is comparable to study by Narra et al who detected neoplastic lesions in 2 cases (4.34\%).[10] Literature[15] reveals that seminoma occurs most commonly in fourth to fifth decade and presents with painless diffuse unilateral testicular enlargement as in our case.

\section{Intratesticular Cyst}

In the present study one case $(3.84 \%)$ of intratesticular cyst was seen sonographically that appeared as well-defined, anechoic lesions with thin, smooth wall and posterior acoustic enhancement near the mediastinum testis. Existing literature ${ }^{[16]}$ states that these cysts are discovered incidentally on sonography in $8 \%$ to $10 \%$ of the male population. The incidence of Intratesticular cyst in this study is comparable to Narra et al,[10] who found 2 cases (4.34\%) of intratesticular cyst. As in our case, Hamm et al reported that the cysts were located near the mediastinum testis.[16]

\section{Cysts of the Tunica Albuginea}

This study detected one case $(3.84 \%)$ of cysts of the tunica albuginea. This presented as a well-defined small (approx. 11 $\mathrm{mm}$ in size) solitary unilocular cystic lesion seen located within the tunica, surrounded by the testis. Though the mean age at presentation is 40 years, $[17]$ our case aged 35 years.

The present study detected slightly higher incidence of funiculitis and scrotal wall cellulitis compared to previous studies. Incidence of hydrocele was significantly higher compared to previous literature. We detected hydrocele in $41.02 \%$ inflammatory condition and $58.97 \%$ in noninflammatory condition. To our knowledge, no such separate categorisation of hydrocele into inflammatory and noninflammatory type was done in any other study till date. Incidence of varicocele was found to be significantly lower, compared to previous literature.

\section{CONCLUSION}

The advantages of high frequency ultrasound and colour Doppler include non-invasiveness, lack of ionising radiation, simplicity, wide availability, cost effectiveness and repeatability.

High frequency ultrasonography is highly sensitive in differentiating solid from cystic scrotal masses and is clearly superior to clinical diagnosis.

It is invaluable in demonstrating normalcy of testes and epididymis in the presence of large hydrocele and also enables clear demonstration of the morphological alterations associated with scrotal diseases.

Colour Doppler sonography is highly sensitive in diagnosing acute scrotal pathology and accurately differentiates testicular ischaemia or torsion from acute inflammatory diseases. In combination with high frequency ultrasonography, colour Doppler is highly sensitive in demonstrating sub-clinical cases of varicocele.

Hence, the present study highly recommends the use of high-frequency ultrasonography and colour Doppler for the evaluation of scrotal pathologies.

\section{REFERENCES}

[1] Rathi R, Gothecha LK, Gujjar R. Role of high resolution ultrasonography and Color Doppler in scrotal pathology. Indian Journal of Basic and Applied Medical Research 2016;5(3):461-5.

[2] Carroll BA, Gross DM. High-Frequency scrotal sonography. Am J Roentgenol 1983;140(3):511-5. 
[3] Mirochnik B, Bhargava P, Dighe MK, et al. Ultrasound evaluation of scrotal pathology. Radiol Clin North Am 2012;50(2):317-32.

[4] Mathukumili C, Bahaddur A. Role of high frequency real time ultrasonography and color Doppler sonography in evaluation of scrotal pathologies. AJOMR 2016;3(2):64-7.

[5] Melkundi SS, Patil S, Chhabra S. Evaluation of testicular lesions, scrotal swellings by high resolution ultrasonography and color Doppler and its correlation with surgical management. Journal of Evolution of Medical and Dental Sciences 2015;4(104):16960-4.

[6] Arger PH, Mulhern CB, Coleman BG, et al. Prospective analysis of the value of scrotal ultrasound. Radiology 1981;141(3):763-6.

[7] Willscher MK, Conway JF, Daly KJ, et al. Scrotal ultrasonography. J Urol 1983;130(5):931-2.

[8] Horstman WG, Middleton WD, Melson GL. Scrotal inflammatory disease: color Doppler US findings. Radiology 1991;179(1):55-9.

[9] Lerner RM, Mevorach RA, Hulbert WC, et al. Color Doppler US in the evaluation of acute scrotal disease. Radiology 1990;176(2):355-8.
[10] Narra R, Pasupuleti B, Kamaraju SK, et al. Sonological evaluation of scrotal pathology by high resolution ultrasound and Color Doppler. IJMRR 2015;3(1):90-6.

[11] Patil V, Shetty SMC. Chronic epididymo orchitis. IJSR 2014;3(12):178-83.

[12] Farriol VG, Comella XP, Agromayor EG, et al. Gray scale power doppler sonographic appearances of acute infla mmatory diseases of the scrotum. J Clin Ultrasound 2000;28(2):67-72.

[13] Gordon LM, Stein SM, Ralls PW. Traumatic epididymitis: evaluation with color Doppler sonography. Am J Roentgenol 1996;166(6):1323-5.

[14] Hricak H, Lue T, Filly RA, et al. Experimental study of the sonographic diagnosis of testicular torsion. J Ultrasound Med 1983;2(8):349-56.

[15] Jacobsen GK, Talerman A. Atlas of germ cell tumors. J Pathol 1989;160:86-87.

[16] Hamm B, Fobbe F, Loy V. Testicular cysts: differentiation with ultrasound and clinical findings. Radiology 1988;168(1):19-23.

[17] Dogra VS, Gottlieb RH, Rubens DJ, et al. Benign intratesticular cystic lesions: ultrasound features. Radiographics 2001;21(Suppl 1): Spec No:S273-281. 